\title{
Simulation study of the optimal distribution of cyanide in a gold leaching circuit
}

\author{
L.R.P. de Andrade Lima ${ }^{a, b, *}$, D. Hodouin ${ }^{a}$ \\ ${ }^{a}$ Department of Mining, Metallurgical, and Materials Engineering, Laval University, Quebec City, Canada G1K $7 P 4$ \\ ${ }^{\mathrm{b}}$ Department of Materials Science and Technology, Federal University of Bahia, C.P. 6974, Salvador, BA 40810-971, Brazil
}

Received 25 September 2005; accepted 1 December 2005

Available online 19 January 2006

\begin{abstract}
The mineral industry has been using cyanidation to recover gold from ores for more than a century; however, a systematic study of the best reactant addition strategy in a cascade of agitated leaching tanks is not available in the open literature. A phenomenological mathematical model of the gold cyanidation process, calibrated with a set of industrial data from an Australian plant, together with an economic performance index is used to analyze this problem. The simulated results show that the best compromise between the two antagonistic effects, cyanide consumption and gold recovery, which are both function of cyanide concentrations, leads to a reagent distribution that depends on the leaching and cyanide consumption kinetics, pulp feed characteristics, and economic factors such as the gold market value. For the specific studied plant, in the operating range of low cyanide consumption and fast gold dissolution, all the cyanide must be added in the first tank; however, in the operating conditions of high cyanide consumption, cyanide has to be distributed in the first, second and third tanks.
\end{abstract}

(C) 2005 Elsevier Ltd. All rights reserved.

Keywords: Cyanidation; Gold ores; Leaching; Modelling; Process optimization; Process synthesis

\section{Introduction}

Leaching by cyanide solutions in aerated alkaline pulp has been the main process for gold extraction from ores for more than one century. In spite of the fact that in the last decades the automatic control of the free cyanide concentration in the leaching section of conventional gold extraction processes has emerged as an useful technology, the cyanide distribution strategy along the leaching cascade is still empirically selected (Brandt et al., 1986; Uys et al., 1987; Flintoff, 1993; Rowden, 1997; Caron et al., 1999). This paper evaluates if an optimal distribution of cyanide along a plant leaching section might improve the process efficiency.

\footnotetext{
* Corresponding author. Present address: Department of Chemical Engineering, McGill University, 3610 University Street, Montreal, Que., Canada H3A 2B2. Tel.: +1 514398 5170; fax: +1 5143986678.

E-mail addresses: luiz.deandradelima@mail.mcgill.ca, lelo@ufba.br (L.R.P. de Andrade Lima).
}

Stage reactant distribution in a cascade of reactors is already employed by the chemical and biochemical industries and systematic studies of optimal distribution strategies are documented (Levenspiel, 1999; Villermaux, 1993; Biegler et al., 1997; Moreira and Malcata, 1996). The mineral processing industry has widely employed stage reactants addition in flotation (Wills, 1997; Lynch et al., 1981) but only a few systematic studies analyzing the effect of the reactant distribution on the process performance are available in the open literature (see for instance, Bazin and Proulx, 2001). In gold processing plants, stage reactants addition is currently used in leaching sections; however, studies on the optimization of their distribution are not available in the open literature.

The mathematical modeling and numerical simulation of gold leaching and gold recovery in agitated tanks by activated carbon using the process of carbon-in-leach and carbon-in-pulp have received a lot of attention since the 1970s and several papers are available, such as: Nicol 


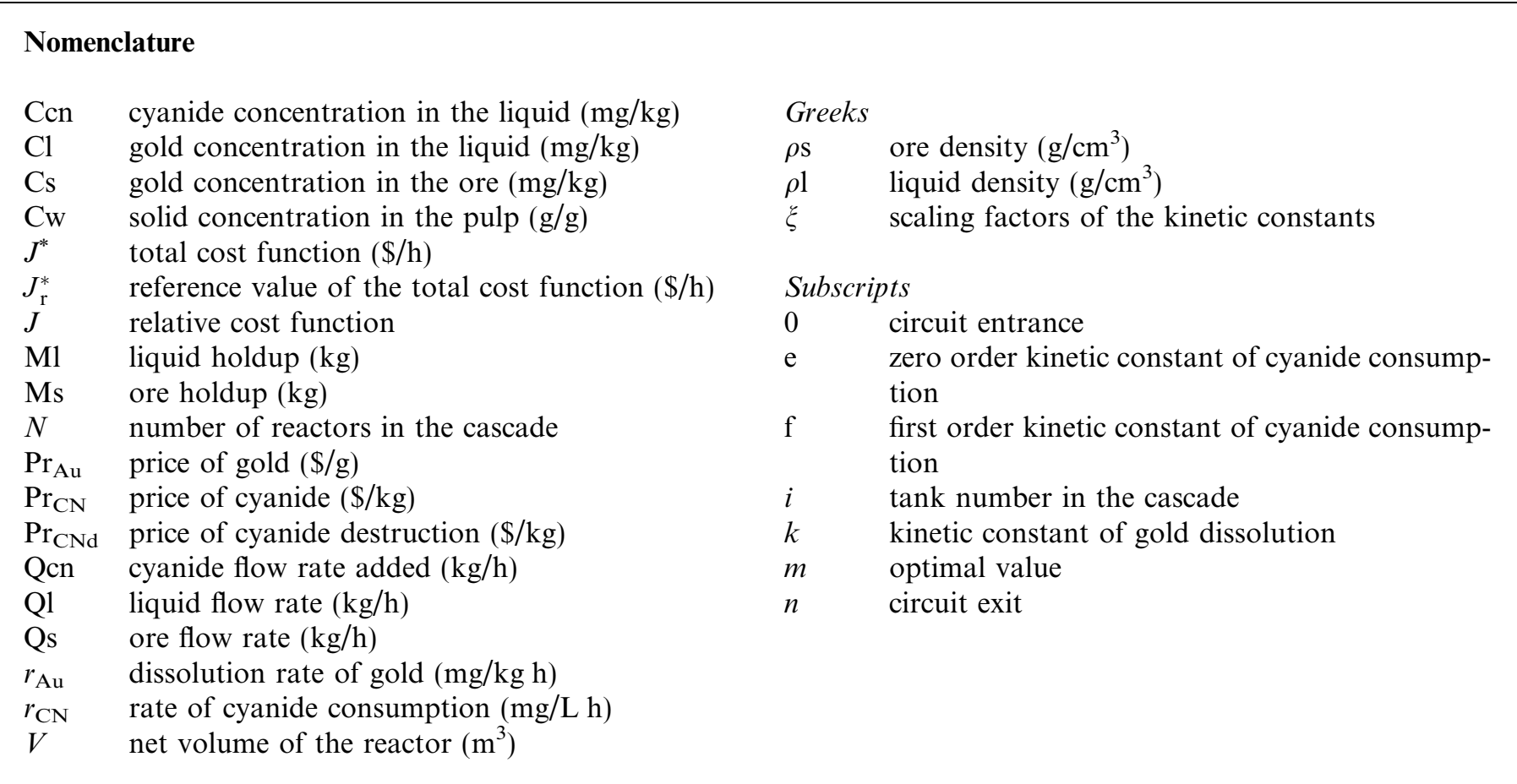

et al. (1984), Williams and Glasser (1985), Carrier et al. (1987), Stange and King (1987), Stange et al. (1990a,b), Woollacott et al. (1990), van Deventer and Ross (1991), van der Walt and van Deventer (1992), Stange (1991, 1999), Schubert et al. (1993), Rees and van Deventer (2001), and Rees et al. (2001). However, only a few works have discussed the systematic design and optimization of these processes (Carrier et al., 1987; Stange, 1991, 1999; Schubert et al., 1993; Rogans et al., 1998; de Andrade Lima and Hodouin, 2005a; de Andrade Lima, in press).

The problem of optimal design of the number and size distribution of reactors in a gold ore leaching plant was recently addressed (de Andrade Lima and Hodouin, 2005a; de Andrade Lima, in press). In these studies, the reactor configuration was described as a series of ideal continuous stirred tank reactors (CSTR), and the reactions were described by kinetic models calibrated with experimental data. The present work uses a similar approach for analyzing the reactant distribution problem in the case of a cascade of three equal-sized leaching tanks, which was never discussed in the open literature. The results presented in this study are specific for a leaching circuit treating a relatively simple ore, but the methodology used can be directly applied to other leaching plants and ores, including

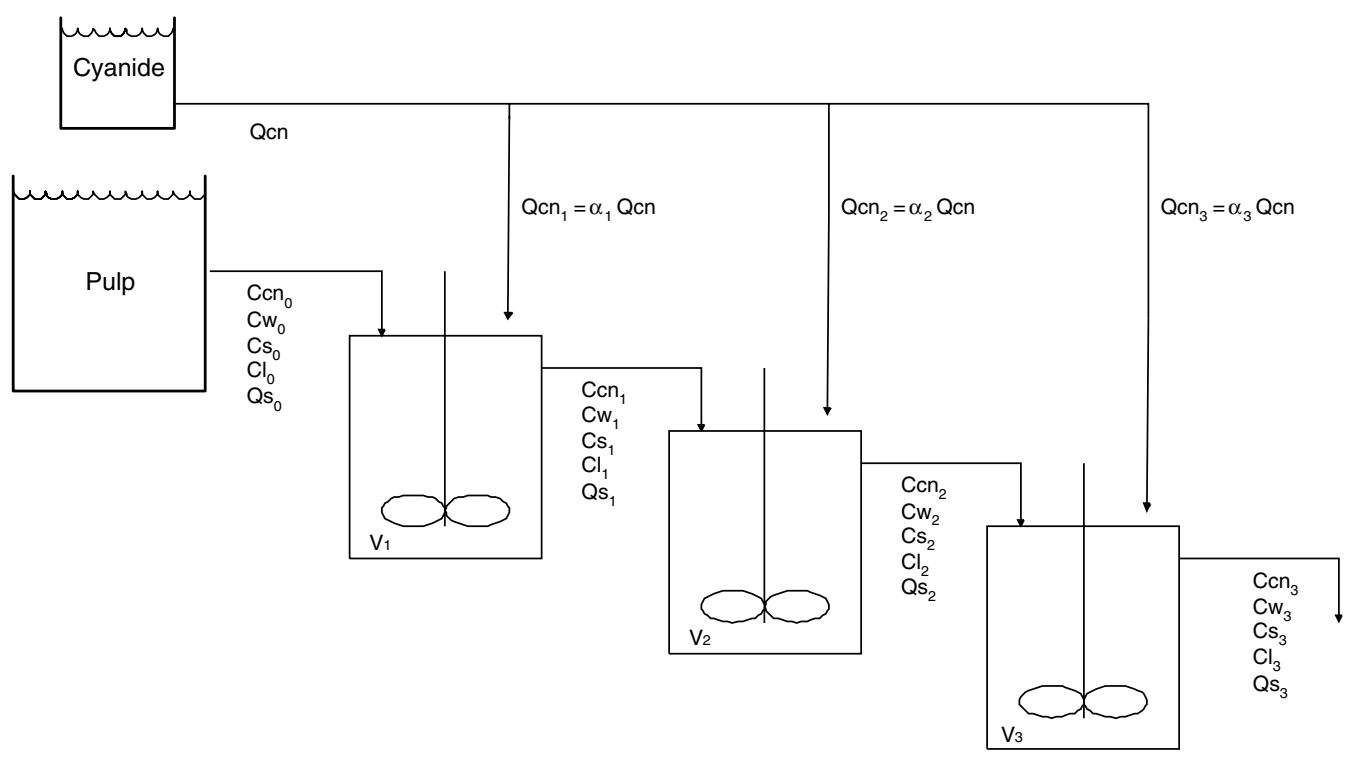

Fig. 1. Schematic diagram of the three-tank leaching plant $\left(V_{i}\right.$ is the reactor volume; Qcn is the cyanide feed rate; $\alpha_{i}$ is the ratio of cyanide feed rate distributed in each tank). 
the carbon-in-leach process, which is not discussed here. Fig. 1 presents the studied cascade of tanks with the corresponding process variables: concentrations $(\mathrm{C})$ and mass flow rates $(\mathrm{Q})$ of each stream, and fractions of the total cyanide flow rate that are fed to the tanks $\left(\alpha_{i}\right)$. More details regarding the plant and process are presented in Section 2.

The paper is organized as follows. Section 2 presents an overview of the mathematical model used to describe the gold cyanidation and defines the cost function. Section 3 presents the results of the optimal cyanide distribution policy, and discusses the sensitivity of the results to the kinetic and economic parameters. Section 4 presents the conclusions.

\section{Gold cyanidation modelling and simulation}

The process model used to assemble the steady-state simulator to design optimal cyanide distribution strategies is based on equations developed in other studies to describe the gold leaching and recovery processes (Carrier et al., 1987; Woollacott et al., 1990; van Deventer and Ross, 1991; van der Walt and van Deventer, 1992; Stange, 1991, 1999; Schubert et al., 1993; de Andrade Lima, 2001, in press; Rees and van Deventer, 2001; Rees et al., 2001; de Andrade Lima and Hodouin, 2005a). In this model, each leaching tank in the circuit is described as CSTRs and the reactions are described by simplified kinetic models. In the present case, the rate of reaction for gold cyanidation and cyanide consumption are described by lumped models calibrated on industrial data. For a tank where the solid flow rate is Qs, the gold balance in the ore is

$$
\frac{\mathrm{Qs}}{\mathrm{Ms}}\left(\mathrm{Cs}_{0}-\mathrm{Cs}\right)-r_{\mathrm{Au}}=0
$$

where $\mathrm{Ms}$ is the ore holdup, $\mathrm{Cs}_{0}$ and $\mathrm{Cs}$ are the input and output ore gold concentration, and $r_{\mathrm{Au}}$ is the gold dissolution rate. The cyanide balance is given by

$\frac{\mathrm{Q}}{\mathrm{Ml}}\left(\mathrm{Ccn}_{0}-\mathrm{Ccn}\right)+\frac{\mathrm{Qcn}}{\mathrm{Ml}}-r_{\mathrm{CN}}=0$

where $\mathrm{Q} 1$ and $\mathrm{Qcn}$ are the liquid and cyanide flow rates, $\mathrm{Ccn}_{0}$ and $\mathrm{Ccn}$ are the input and output cyanide concentrations, and $r_{\mathrm{CN}}$ is the cyanide consumption rate. Ml, the liquid holdup, is obtained through the assumption that the solid and liquid phases are perfectly mixed

$\mathrm{Ml}=\frac{\mathrm{Qs}}{\mathrm{Q} 1} \mathrm{Ms}$

Cyanidation of gold ores is a complex heterogeneous process, where the leaching behavior of gold depends upon the nature of the gold bearer as well of its distribution within the ore with respect to its ability to be reached by the liquid phase. Also it depends on the quality of the gold surface exposed to cyanide. Some attempts have been made to relate the kinetic rate to the particle size (de Andrade Lima and Hodouin, 2005b) and liberation (Lorenzen and van Deventer, 1994). However, in the present study, a lumped kinetic model, based on an overall rate of cyanidation, is used, because it seems to be enough for the objective of illustrating the importance of a proper selection of the cyanide distribution strategy, and does not change the trends that will be identified. Furthermore, it is assumed that operating conditions other than the cyanide concentrations are maintained at constant values (constant $\mathrm{pH}$ and oxygen saturation for all the tanks) (de Andrade Lima et al., 2002; de Andrade Lima and Hodouin, 2005a; de Andrade Lima, in press).

The cyanide consumption kinetics is also described by a lumped kinetic model, assuming an average rate for the particle population. Two superimposed effects are assumed to explain the rate of cyanide consumption. The first one is related to the reaction with metal species contained in the mineral phases. It is modeled as a zero order process, since, for a given mineralogical composition of the ore, the cyanicide exposed surfaces are constant. The second one, described as a first order process, explains the cyanide consumption effect due to the free cyanide content itself, such as the losses by hydrolysis to hydrogen cyanide and ammonia, and the oxidation to cyanate or cyanogens (Adams, 1990; de Andrade Lima et al., 2002).

The rate equations that describe the gold leaching process are calibrated with data from a plant that treats about $400 \mathrm{t} / \mathrm{h}$ of ores coming from twelve ore bodies located in the northern part of the Saddleback greenstone belt, located in the southwestern corner of the Yilgarn craton, Western Australia (Wilde and Pidgeon, 1986; Bax, 1996; de Andrade Lima, 2001; de Andrade Lima et al., 2002; Groves et al., 2003). The ore contains basalt and small amounts of marcassite $\left(\mathrm{FeS}_{2}\right)$, chalcopyrite $\left(\mathrm{CuFeS}_{2}\right)$, galena $(\mathrm{PbS})$, sphalerite $(\mathrm{ZnS})$, gersdorffite $(\mathrm{NiAsS})$ and arsenopyrite (FeAsS), but reactive sulfides, such as, pyrite $\left(\mathrm{FeS}_{2}\right)$ and pyrrhotite $\left(\mathrm{Fe}_{1-x} \mathrm{~S}\right)$ are almost absent (Wilde and Pidgeon, 1986; Bax, 1996; Allibone et al., 1998; Groves et al., 2003). The gold in the ore is well liberated and 20 to $40 \%$ is concentrated using gravity methods in the grinding circuit. The ore size in the leaching circuit is about $50 \%$ less than $38 \mu \mathrm{m}$. The pulp in the leaching circuit has a concentration of solids of about $45 \%$, and the water used in this circuit is salted with a total concentration of dissolved solids higher than $12 \%$. Neither lead nitrate addition nor pretreatment is used in the studied plant. The leaching section of this plant has three mechanically agitated tanks with nominal volume of $2000 \mathrm{~m}^{3}$, and the free cyanide concentration is measured automatically using a Kegold electrode and controlled at $450 \mathrm{mg} / \mathrm{L}$ by addition of sodium cyanide at the entrance of the first tank. Oxygen is added to the first two leaching tanks, and its concentration is not continuously measured, but due to the absence of reactive species in the ore, for simulation purposes, it is assumed as constant at the saturation value. The $\mathrm{pH}$ is also automatically measured in the outlet of the first tank and controlled at 10.2 by addition of calcium oxide at the comminution section of the plant (Bax, 1996). 
The leaching section of the plant was sampled at each hour, simultaneously with the entry and the outlet side of each tank, during $37 \mathrm{~h}$. The liquid phase, after filtration of the sampled pulp was analyzed. The $\mathrm{pH}$ was measured with a standard $\mathrm{pH}$-meter, the cyanide concentration determined by titration with silver nitrate and rhodanine, and the concentration of gold measured by atomic absorption spectrophotometry after the extraction of this metal by di-iso-butyl-ketone (DIBK). The solids were washed and the ore gold content measured by fire assay and atomic absorption spectrophotometry. The concentration of the solids was also given for each sample. At every $2 \mathrm{~h}$, samples of the pulp were taken and filtered to measure the concentration of carbon in the tanks and their gold content measured by fire assay and atomic absorption spectrophotometry (Bax, 1996).

The ore flow rate time evolution was measured in the entrance of the comminution-leaching section of the plant, but not in the leaching-adsorption circuit entrance (Bax, 1996); therefore, estimated values were produced by assuming that the comminution circuit behaves as a second order system with a time constant of $0.37 \mathrm{~h}$.

The fitted kinetic models for the three-tank plant described above are (de Andrade Lima, 2001, 2002)

$r_{\mathrm{Au}}=5.50 \times 10^{-3} \mathrm{Ccn}(\mathrm{Cs}-0.14)^{2.15}(\mathrm{mg} / \mathrm{kg} \mathrm{h})$
$r_{\mathrm{CN}}=3.43+1.47 \times 10^{-2} \mathrm{Ccn}(\mathrm{mg} / \mathrm{kg} \mathrm{h})$

where $\mathrm{Ccn}$ is the free cyanide concentration in the liquid phase and $\mathrm{Cs}$ is the ore gold content. Because of the assumption of perfect mixing these values are assumed to be equal to the output concentration values. The $0.14 \mathrm{mg} / \mathrm{kg}$ value in Eq. (4) is the measured residual gold concentration in the solid phase. The net reactor volume $(V)$ was estimated as $1160 \mathrm{~m}^{3}$, leading to a nominal mean residence time of the slurry of about $1.8 \mathrm{~h}$ in each tank.

The process simulation was performed by sequential numerical resolution of Eqs. (1)-(5) for each leaching reactor. Fig. 2 shows the simulated results of the concentration profiles and flow rates in the three-tanks plant. The cyanide concentrations, ore gold concentrations, and liquid phase gold concentrations are close to the average measured values, and the cyanide consumption, the gold dissolution and the enrichment of the liquid from tank to tank are well reproduced by the simulator (de Andrade Lima, 2001, 2002).

A performance criterion is required to tune the cyanide addition strategy. The following cost function that includes the cyanide cost, the residual pulp treatment cost, and a penalty for the loss of non-dissolved gold is used (de Andrade Lima and Hodouin, 2005a; de Andrade Lima, in press):

$J^{*}=\left(\sum_{i=1}^{N} \mathrm{Qcn}_{i}+\mathrm{Ccn} n_{0} \mathrm{Q}\right) \operatorname{Pr}_{\mathrm{CN}}+(\mathrm{Q} 1+\mathrm{Qs}) \operatorname{Pr}_{\mathrm{CNd}}+\left(\mathrm{Cs}_{n} \mathrm{Qs}\right) \operatorname{Pr}_{\mathrm{Au}}$

where $\mathrm{Qcn}_{i}$ is the cyanide flow rate added to the $i$ th tank, $\mathrm{Ccn}_{0}$ is the cyanide concentration at the first tank entrance, $N$ is the number of tanks in the cascade, $\operatorname{Pr}_{\mathrm{CN}}$ is the cyanide price, $\operatorname{Pr}_{\mathrm{CNd}}$ is the cost of destruction of the residual cyanide, $\mathrm{Cs}_{n}$ is the ore gold concentration at the last tank outlet, and $\operatorname{Pr}_{\mathrm{Au}}$ is the gold market value. Typical values for the cyanide purchase and destruction costs, and for the gold value were respectively $1.35 \$ / \mathrm{kg}, 1.75 \$ / \mathrm{t}$, and $10 \$ / \mathrm{g}$, at the time the simulation was performed (\$ stands for US\$). The cost function $\left(J^{*}\right)$ is given in $\$$ per time unit. The operation is profitable if the operating and capital costs are lower than the value of the extracted gold. The operation profit is optimized relatively to a reference state. For that purpose, the cost function $\left(J^{*}\right)$ is normalized using a reference cost $\left(J_{\mathrm{r}}^{*}\right)$ as follows:

$J=\left(J^{*}-J_{\mathrm{r}}^{*}\right) / J_{\mathrm{r}}^{*}$

The reference cost is chosen in the case when $\mathrm{Qcn}_{1}=$ $100 \mathrm{~kg} / \mathrm{h}, \quad \mathrm{Qcn}_{2}=\mathrm{Qcn}_{3}=0, \quad \mathrm{Ccn}_{0}=200 \mathrm{mg} / \mathrm{L}, \quad \operatorname{Pr}_{\mathrm{Au}}=$ $5 \$ / \mathrm{g}$, that is $J_{\mathrm{r}}^{*}=2409 \$ / \mathrm{h}$.

\section{Results and discussion}

In a first simulation run, the normalized cost function (Eq. (7)) is evaluated for different strategies of cyanide distribution to the tanks. The amount of total added cyanide is $0,10,100,200$, or $1000 \mathrm{~kg} / \mathrm{h}$, and it is assumed to be injected in only one tank, the first, the second or the third.

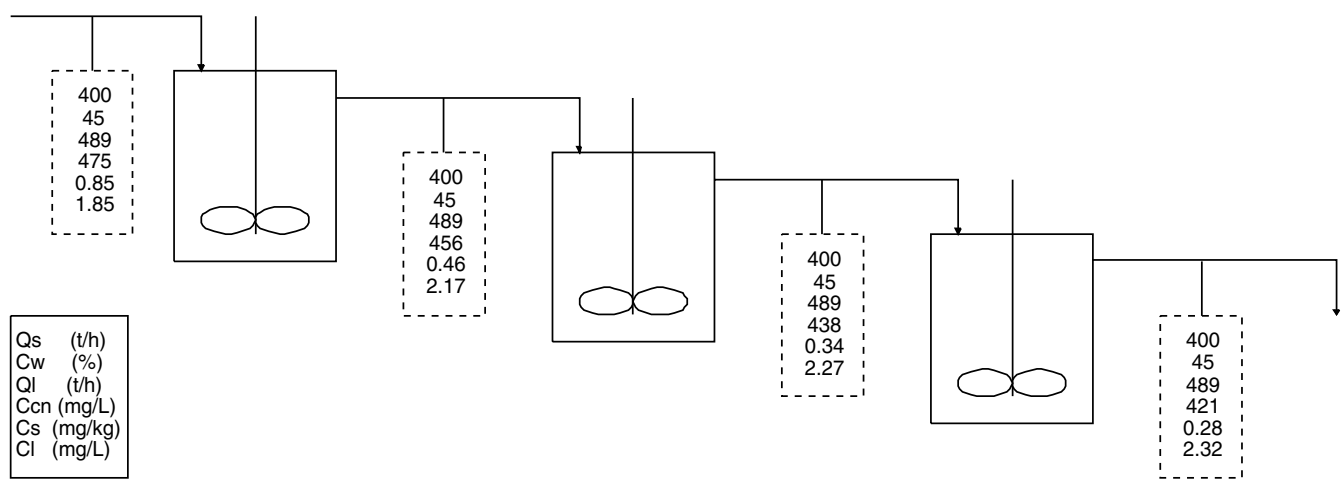

Fig. 2. Results of the simulation of the nominal regime of the three-tank leaching plant. The variables shown are: ore flow rate (Qs), solid concentration in the pulp $(\mathrm{Cw})$, liquid flow rate $(\mathrm{Ql})$, cyanide concentration in the liquid phase $(\mathrm{Ccn})$, ore gold content $(\mathrm{Cs})$, and gold concentration in the liquid phase $(\mathrm{Cl})$. 
As cyanide is also added before the leaching circuit, the simulations are performed for different values of this parameter, assuming that the cyanide concentration at the plant entrance $\left(\mathrm{Ccn}_{0}\right)$ can be 0,200 or $475 \mathrm{mg} / \mathrm{L}$. The simulations are also performed for constant feed gold content in the ore $\mathrm{Cs}_{0}(0.85 \mathrm{mg} / \mathrm{kg})$ and in the liquid phase $(1.85 \mathrm{mg} / \mathrm{L})$ and for three different conditions of the gold market values at 5, 10 and $15 \$ / \mathrm{g}$. Table 1 shows the results of the normalized cost function $(J$ in \%) as a function of the added cyanide flow rate $\left(\mathrm{Qcn}_{i}\right)$, the gold price $\left(\operatorname{Pr}_{\mathrm{Au}}\right)$, and the initial cyanide concentration. For each gold price and initial cyanide concentration, there is a lowest value of $J$ (value underlined). This is not necessarily an optimal value since the operating conditions that are applied are located on a discrete grid of conditions. However, it is clear that the optimal operating point is varying with the gold price and the feed conditions. These preliminary simulations show that, for the ore tested and the operating range selected, the cost function is the lowest when the addition of cyanide is made in the first tank. This is related to the large amount of gold dissolution that takes place in the first tank of the cascade, for the specific ore tested.

To study the effect of continuous variations of the cyanide addition in the first and second tanks $\left(\mathrm{Qcn}_{1}\right.$ and Qcn $)$, the gold price $\left(\operatorname{Pr}_{\mathrm{Au}}\right)$ was maintained at a value of $10 \$ / \mathrm{g}$, for two levels of cyanide concentration at the plant feed $\left(\mathrm{Ccn}_{0}=0\right.$ or $\left.475 \mathrm{mg} / \mathrm{L}\right)$. The simulated values of the normalized cost function $(J)$, as a function of both cyanide addition rates, are presented as contour plots in Fig. 3(a) and (b). These plots show a minimum value on the cyanide flow rate in the first tank axis $\left(\mathrm{Qcn}_{1}\right)$, which, for these two cases, clearly shows that the optimal result occurs when the cyanide is added in the first tank only. The monotonic behavior of these surfaces indicates that there is no prob-
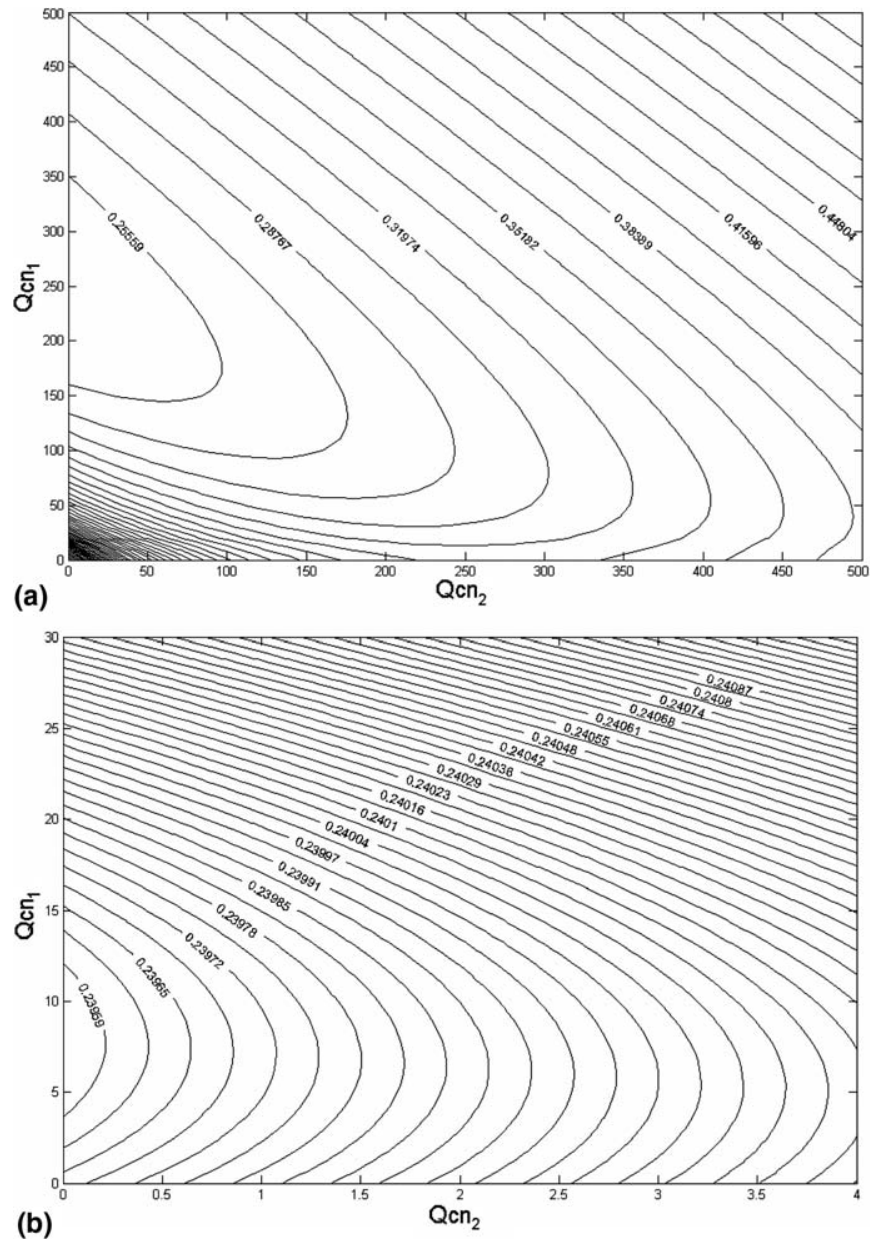

Fig. 3. Contour plots of the normalized cost function $(J)$ as a function of the free cyanide flow rates in the first $\left(\mathrm{Qcn}_{1}\right)$ and the second tank $\left(\mathrm{Qcn}_{2}\right)$ for cyanide concentration in the leaching section entrance $\left(\mathrm{Ccn}_{0}\right)$ equal to: (a) $0 \mathrm{mg} / \mathrm{L}$; (b) $475 \mathrm{mg} / \mathrm{L}$

Table 1

Normalized cost $(J$ in $\%)$ as a function of the cyanide addition strategy in the leaching tank cascade $\left(\mathrm{Qcn}_{i}\right)$, for various gold prices $\left(\operatorname{Pr}_{\mathrm{Au}}\right)$, and initial cyanide feed concentrations $\left(\mathrm{Ccn}_{0}\right)$

\begin{tabular}{|c|c|c|c|c|c|c|c|c|c|c|c|}
\hline \multirow[t]{4}{*}{$\mathrm{Qcn}_{1}(\mathrm{~kg} / \mathrm{h})$} & \multirow[t]{4}{*}{$\mathrm{Qcn}_{2}(\mathrm{~kg} / \mathrm{h})$} & \multirow[t]{4}{*}{$\mathrm{Qcn}_{3}(\mathrm{~kg} / \mathrm{h})$} & \multicolumn{9}{|c|}{$\mathrm{Ccn}_{0}(\mathrm{mg} / \mathrm{L})$} \\
\hline & & & \multicolumn{3}{|l|}{0} & \multicolumn{3}{|l|}{200} & \multicolumn{3}{|l|}{475} \\
\hline & & & \multicolumn{3}{|c|}{$\operatorname{Pr}_{\mathrm{Au}}(\$ / \mathrm{g})$} & \multicolumn{3}{|c|}{$\operatorname{Pr}_{\mathrm{Au}}(\$ / \mathrm{g})$} & \multicolumn{3}{|c|}{$\operatorname{Pr}_{\mathrm{Au}}(\$ / \mathrm{g})$} \\
\hline & & & 5 & 10 & 15 & 5 & 10 & 15 & 5 & 10 & 15 \\
\hline 0 & 0 & 0 & 35.17 & 105.75 & 176.33 & 0.65 & 31.23 & 61.82 & $\underline{0.79}$ & 23.97 & 47.15 \\
\hline 10 & 0 & 0 & 28.65 & 92.15 & 155.65 & 0.22 & 29.81 & 59.41 & 1.06 & 23.96 & 46.86 \\
\hline 0 & 10 & 0 & 28.94 & 92.73 & 156.52 & 0.49 & 30.35 & 60.22 & 1.13 & 24.11 & 47.08 \\
\hline 0 & 0 & 10 & 31.15 & 97.15 & 163.16 & 0.82 & 31.02 & 61.21 & 1.23 & 24.30 & 47.37 \\
\hline 100 & 0 & 0 & 0.54 & 30.89 & 61.25 & $\underline{0.00}$ & 24.33 & 48.66 & 4.16 & 25.11 & $\underline{46.07}$ \\
\hline 0 & 100 & 0 & 6.10 & 42.01 & 77.92 & 1.37 & 27.07 & 52.77 & 4.68 & 26.15 & 47.62 \\
\hline 0 & 0 & 100 & 16.55 & 62.91 & 109.27 & 3.35 & 31.03 & 58.71 & 5.41 & 27.61 & 49.81 \\
\hline 200 & 0 & 0 & $\underline{0.04}$ & 24.29 & 48.54 & 2.87 & 24.45 & 46.04 & 8.39 & 27.96 & 47.54 \\
\hline 0 & 200 & 0 & 4.93 & 34.07 & 63.21 & 4.54 & 27.81 & 51.07 & 9.14 & 29.48 & 49.81 \\
\hline 0 & 0 & 200 & 15.47 & 55.15 & 94.84 & 7.24 & 33.20 & 59.16 & 10.29 & 31.77 & 53.25 \\
\hline 1000 & 0 & 0 & 37.01 & 53.38 & 69.76 & 42.22 & 58.34 & 74.45 & 49.46 & 65.26 & 81.06 \\
\hline 0 & 1000 & 0 & 39.76 & 58.88 & 78.00 & 43.76 & 61.42 & 79.07 & 50.46 & 67.27 & 84.08 \\
\hline 0 & 0 & 1000 & 47.88 & 75.14 & 102.39 & 47.13 & 68.14 & 89.16 & 52.42 & 71.19 & 89.96 \\
\hline
\end{tabular}


Table 2

Minimal normalized cost $(J)$ and optimal cyanide addition rates $\left(\mathrm{Qcn}_{i m}\right.$, as a function of the feed ore gold content and cyanide concentration $\left(\mathrm{Cs}_{0}\right.$, and $\left.\mathrm{Ccn}_{0}\right)$

\begin{tabular}{lcclll}
\hline $\begin{array}{l}\mathrm{Cs}_{0} \\
(\mathrm{mg} / \mathrm{kg})\end{array}$ & $\begin{array}{l}\mathrm{Ccn}_{0} \\
(\mathrm{mg} / \mathrm{L})\end{array}$ & $\begin{array}{l}\mathrm{Qcn}_{1 m} \\
(\mathrm{~kg} / \mathrm{h})\end{array}$ & $\begin{array}{l}\mathrm{Qcn}_{2 m} \\
(\mathrm{~kg} / \mathrm{h})\end{array}$ & $\begin{array}{l}\mathrm{Qcn}_{3 m} \\
(\mathrm{~kg} / \mathrm{h})\end{array}$ & $J(\%)$ \\
\hline 0.3 & 0 & 95.72 & 0 & 0 & 11.04 \\
0.3 & 200 & 0 & 0 & 0 & 11.04 \\
0.3 & 475 & 0 & 0 & 0 & 13.84 \\
0.85 & 0 & 240.0 & 0 & 0 & 23.96 \\
0.85 & 200 & 142.3 & 0 & 0 & 23.96 \\
0.85 & 475 & 7.85 & 0 & 0 & 23.96 \\
10 & 0 & 378.9 & 0 & 0 & 39.05 \\
10 & 200 & 281.1 & 0 & 0 & 39.05 \\
10 & 475 & 146.7 & 0 & 0 & 39.05 \\
\hline
\end{tabular}
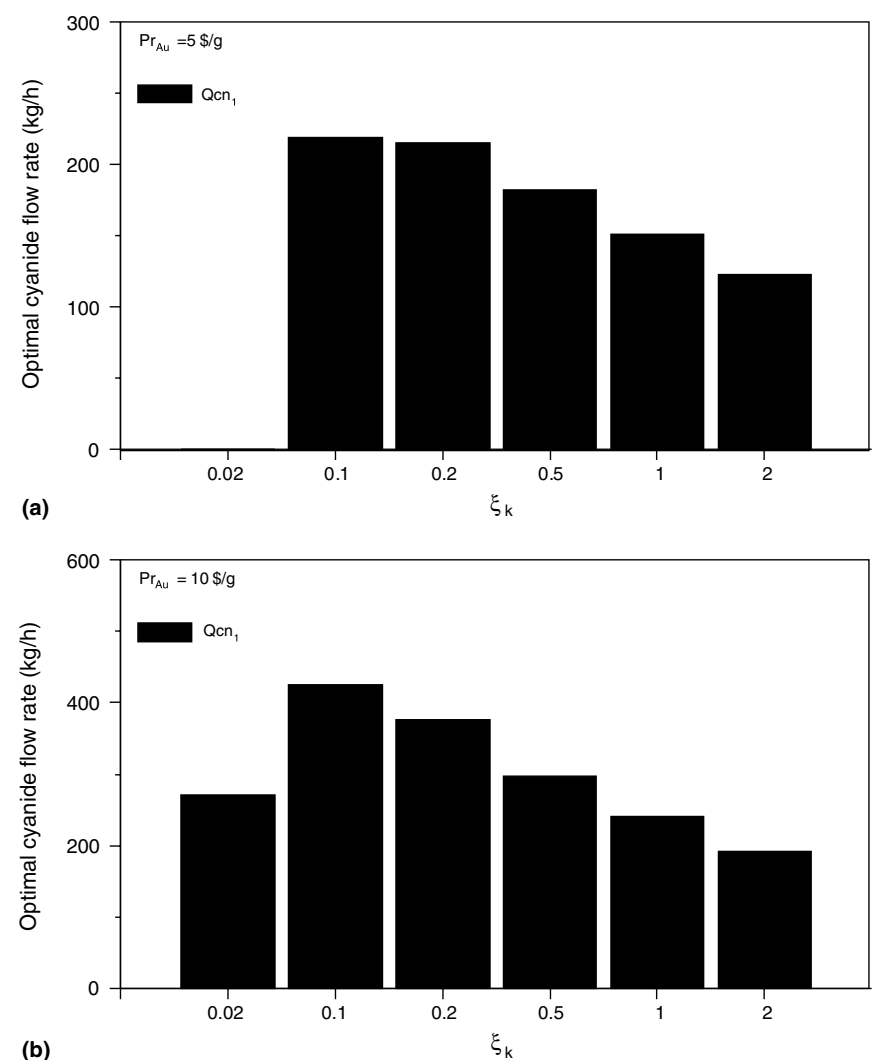

(b)

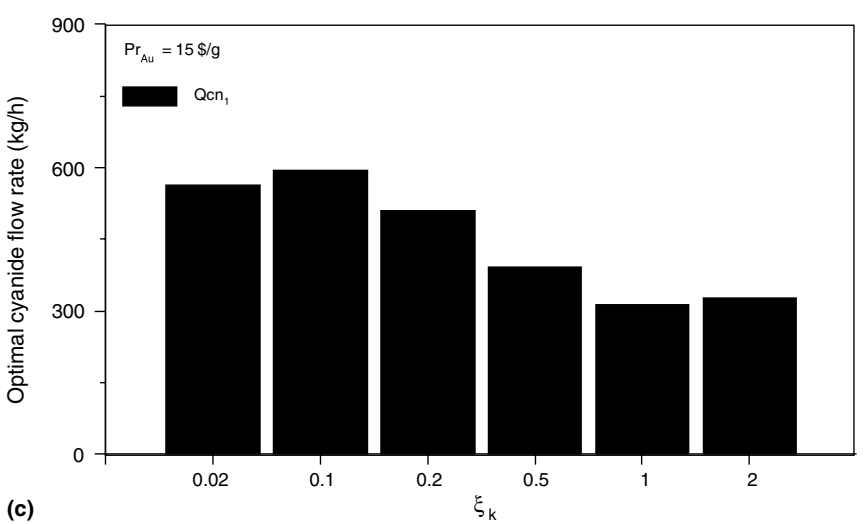

Fig. 4. Effect of the gold leaching kinetics ( $\xi_{k}$ parameter) on the optimal free cyanide distribution in the first tank $\left(\mathrm{Qcn}_{1 m}\right)$ for three values of the gold price $\left(\operatorname{Pr}_{\mathrm{Au}}\right)$ : (a) $5 \$ \mathrm{~g}$; (b) $10 \$ / \mathrm{g}$; (c) $15 \$ / \mathrm{g}$. lem to find the optimal values using classical minimization methods, such as the conjugate directions method (Biegler et al., 1997) that is used in this study.

The optimal cyanide distribution $\left(\mathrm{Qcn}_{i m}\right)$ and normalized cost function $(J$ in \%) are calculated using the above method for feed cyanide concentrations $\left(\mathrm{Ccn}_{0}\right)$ equal to 0,200 and $475 \mathrm{mg} / \mathrm{L}$, a gold price $\left(\operatorname{Pr}_{\mathrm{Au}}\right)$ equal to $10 \$ / \mathrm{g}$, and for varying ore gold content in the leaching plant feed $\left(\mathrm{Cs}_{0}=0.3,0.85\right.$, and $10 \mathrm{mg} / \mathrm{kg}$ ) (see Table 2). In all optimal cases, cyanide must be added only in the first tank, because of the fast dissolution of gold in this specific ore. For a rich ore, the cost function $(J)$ is independent of the cyanide concentration at the circuit entrance, because the cyanide added in the tank compensates exactly the missing amount in the circuit feed. In the case of an ore of low gold content and a moderate cyanide concentration, the optimal flow rates are zero. This is an indication that a cyanide concentration of $200 \mathrm{mg} / \mathrm{L}$ is already too high for a low-grade ore.

The optimal cyanide distribution pattern described above is valid for the specific ore investigated. It is interesting to study how this pattern varies with the kinetic parameters involved in the cyanidation process. The cyanide consumption kinetics may strongly depend on the slurry chemical composition, in particular chemical species, such as iron and copper-bearing minerals, consume cyanide and can significantly change the process profitability. Also the gold dissolution kinetics may vary with the type of ore and the particle size distribution. In order to analyze the sensitivity of the optimal cyanide distribution pattern to the changes of the cyanide consumption and gold dissolution kinetics, several simulation tests were carried out, multiplying the reference values of the coefficients of Eqs. (4) and (5), by a scaling factor $\xi$ that reduces or increases their values. In all cases, the minimum of the normalized cost function $(J$ in $\%)$ and the best cyanide flow rate distribution are calculated. The results are analyzed for feed cyanide

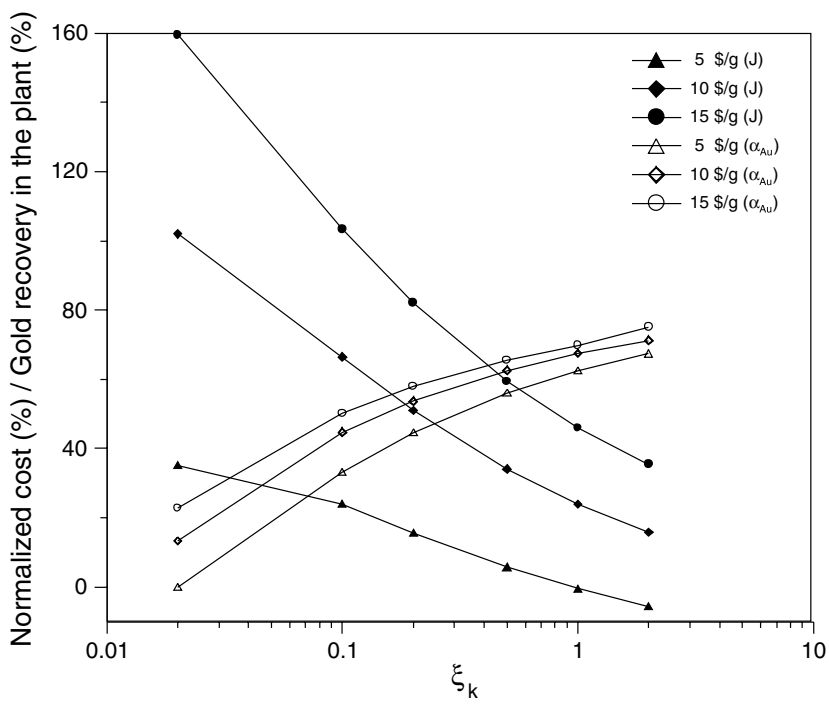

Fig. 5. Effect of the gold leaching kinetics $\left(\xi_{k}\right.$ parameter $)$ on the normalized cost function $(J)$ and the gold recovery in the leaching plant $\left(\alpha_{\mathrm{Au}}=1-\mathrm{Cs}_{n} / \mathrm{Cs}_{0}\right)$ for three values of the gold price $\left(\operatorname{Pr}_{\mathrm{Au}}\right)$. 
concentrations $\left(\mathrm{Ccn}_{0}\right)$ equal to $0 \mathrm{mg} / \mathrm{L}$, for a gold price $\left(\operatorname{Pr}_{\mathrm{Au}}\right)$ equal to 5,10 and $15 \$ / \mathrm{g}$, and for constant feed gold contents in the solid and liquid phase of $0.85 \mathrm{mg} / \mathrm{kg}$ and $1.85 \mathrm{mg} / \mathrm{L}$.

To study the sensitivity of the optimal tuning to the gold dissolution kinetics, the reference value of the kinetic constant is multiplied by a factor $\xi_{k}$ equal to $0.02,0.1,0.2,0.5$, 1 and 2 . In the tested range, all the cyanide must, again, be added to the first tank, and the results are summarized in Figs. 4(a)-(c), and 5. As expected, the lowest is the dissolution rate, the highest should be the cyanide concentration, but the lower are the gold recovery and the revenue of the operation. Obviously, for slow gold dissolution, the size of
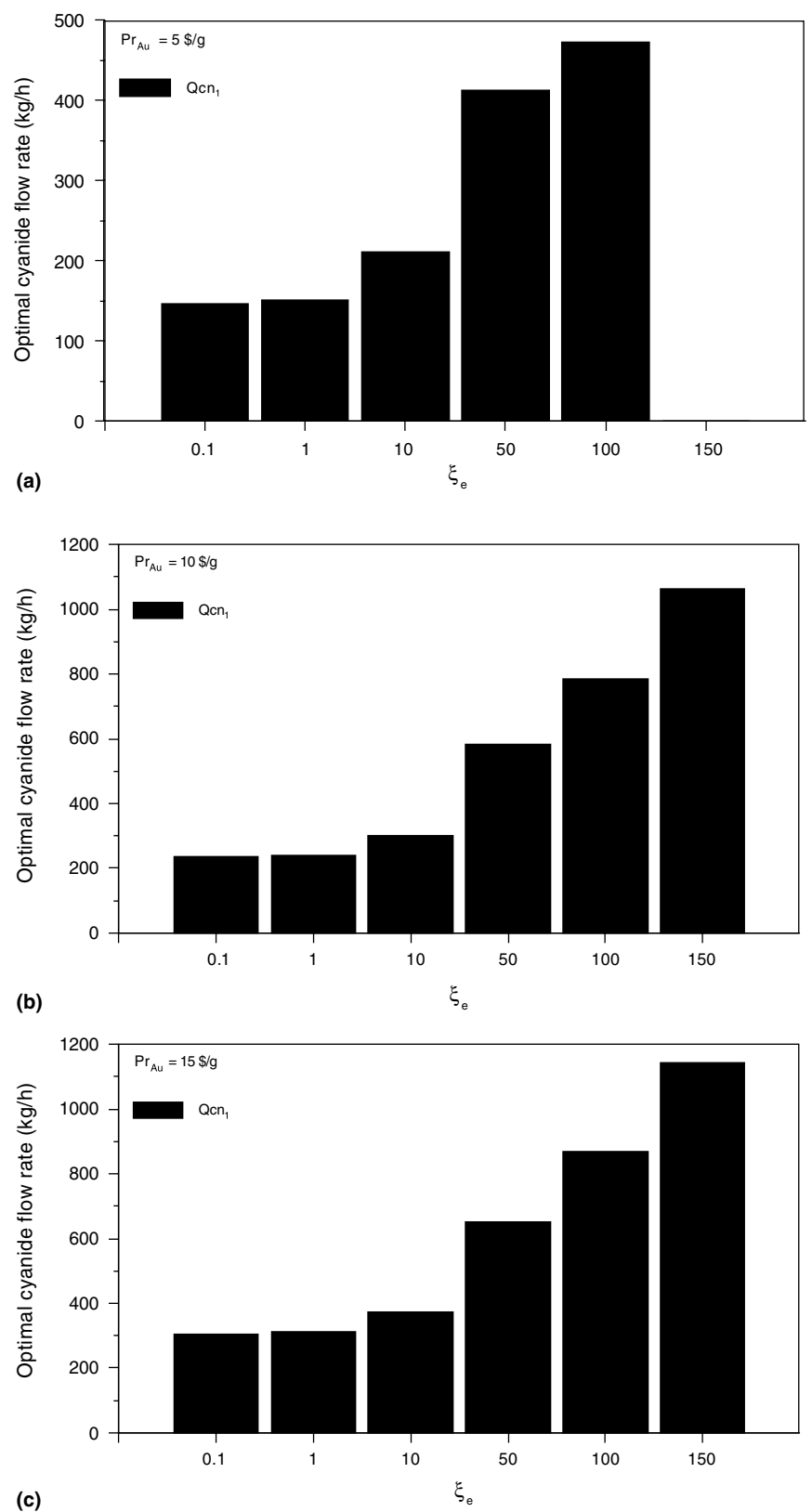

Fig. 6. Effect of the cyanide consumption kinetics ( $\xi_{\mathrm{e}}$ parameter) on the optimal free cyanide distribution in the first tank $\left(\mathrm{Qcn}_{1 \mathrm{~m}}\right)$ for three values of the gold price $\left(\operatorname{Pr}_{\mathrm{Au}}\right)$ : (a) $5 \$ / \mathrm{g}$; (b) $10 \$ / \mathrm{g}$; (c) $15 \$ / \mathrm{g}$. the plant should be increased for lengthening the ore residence time. On the contrary, an increase of the dissolution rate improves the operation profitability.

To study the sensitivity of the optimal tuning to the cyanide consumption kinetics, first, the reference value of the zero-order kinetic coefficient is multiplied by a factor $\xi_{\mathrm{e}}$ equal to $0.1,1,10,50,100$, and 150 . Again, all the cyanide must be added to the first tank, and the results are summarized in Figs. 6(a)-(c) and 7. Obviously, the plant profitability decreases as the cyanide consumption increases, thus limiting the gold recovery. The reference value of the first order kinetic coefficient of cyanide consumption is then multiplied by a factor $\xi_{\mathrm{f}}$ equal to $0.1,1,10,30,40,50$, 100, 200, and 500, and the results are summarized in Figs. $8(\mathrm{a})-$ (c) and 9. Here the cyanide distribution pattern is quite different, since it is necessary to distribute the cyanide into the three tanks, because the cyanide consumption rate is proportional to its concentration. The profitability of the plant decreases as the cyanide consumption increases. The study shows that when the cyanide consumption increases due to the presence of 'cyanicide minerals' or due to changes in the $\mathrm{pH}$, the temperature or the exchanges with the gas phase, it is important to change the distribution of the reagents in the leaching circuit to avoid premature and useless consumption of the cyanide.

As shown by the above results, the gold price is also a key factor in the tuning of a leaching circuit that treats a relatively simple ore, without cyanide-soluble copper, reactive sulfides, preg-robbers, and polysulfides, in a conventional cascade of agitated tanks as in the present case. As a consequence, this factor must be taken into account not only for the global development of gold mines, but also for the current tuning of the leaching operations in these plants.

The economic importance of a proper tuning of the cyanide addition to the leaching circuit, can be roughly understand by simply saying that a decrease by $1 \%$ of the

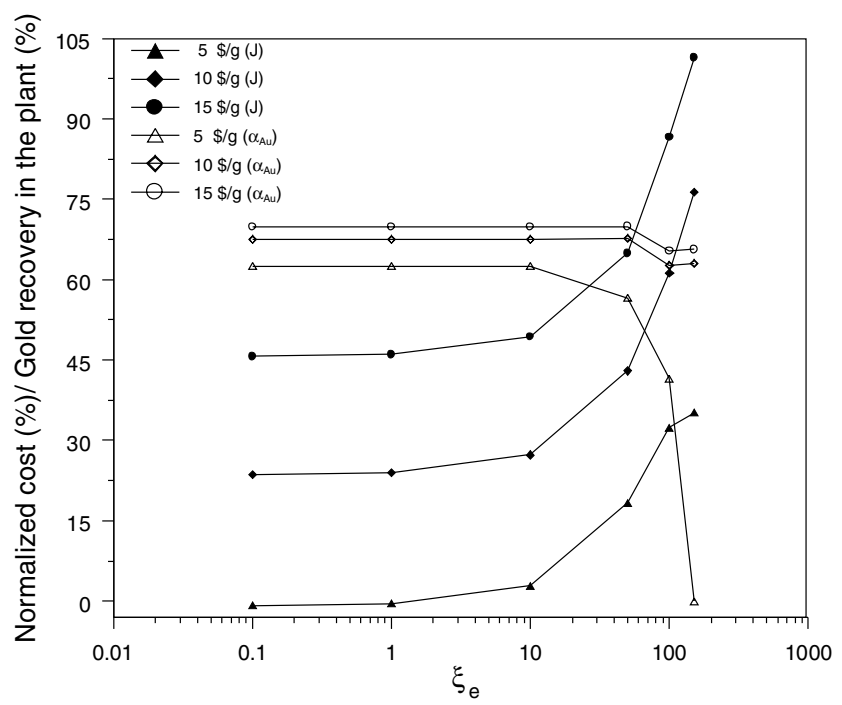

Fig. 7. Effect of the gold leaching kinetics ( $\xi_{\mathrm{e}}$ parameter) on the normalized cost function $(J)$ and the gold recovery in the leaching plant $\left(\alpha_{\mathrm{Au}}=1-\mathrm{Cs}_{n} / \mathrm{Cs}_{0}\right)$ for three values of the gold price $\left(\operatorname{Pr}_{\mathrm{Au}}\right)$. 

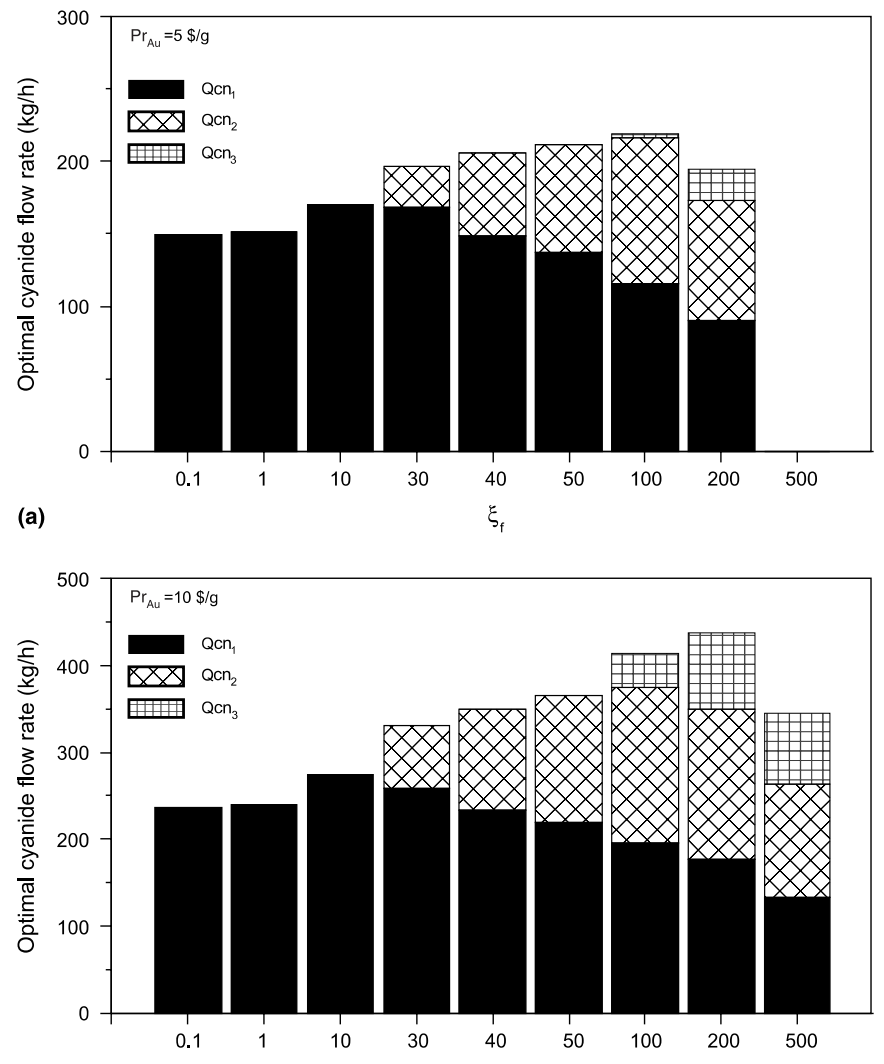

(b)

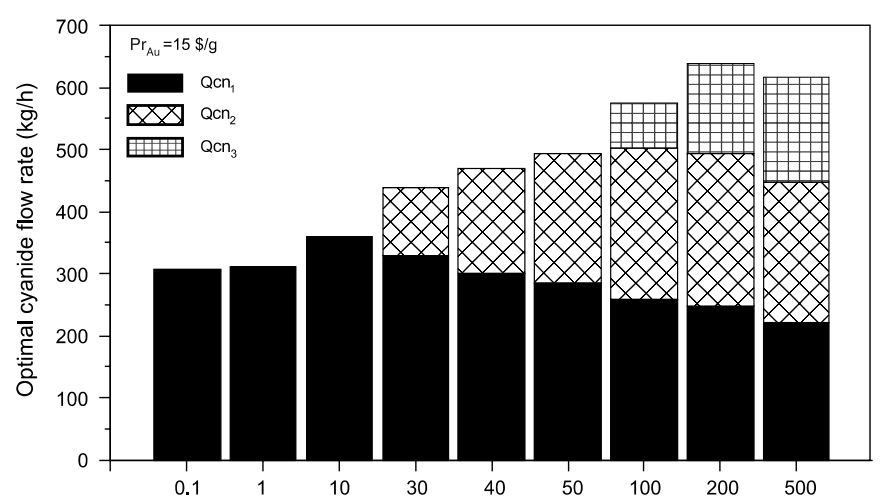

(c)

$\xi_{f}$

Fig. 8. Effect of the cyanide consumption kinetics $\left(\xi_{\mathrm{f}}\right.$ parameter $)$ on the optimal free cyanide distribution $\left(\mathrm{Qcn}_{i m}\right)$ for three values of the gold price $\left(\operatorname{Pr}_{\mathrm{Au}}\right)$ : (a) $5 \$ \mathrm{~g}$; (b) $10 \$ / \mathrm{g}$; (c) $15 \$ / \mathrm{g}$.

gold recovery in the leaching plant, a value which corresponds to only a decrease of the overall plant recovery of approximately $0.4 \%$, corresponds to an annual loss of $350,000 \$$ for a gold at $10 \$ / \mathrm{g}$, and that an over-consumption of cyanide by $5 \%$, in the leaching circuit only (i.e. not considering the cyanide added in the grinding circuit), corresponds to a loss of $180,000 \$$ per year. The economic impact associated to the right distribution of cyanide is significant. It can be evaluated by taking, as an example, the first case presented in Fig. 8 where there is a distribution of cyanide into two tanks $\left(\xi_{\mathrm{f}}=30\right)$. If instead of distributing cyanide in the two first tanks ( 258 and $72 \mathrm{~kg} / \mathrm{h}$ respectively)

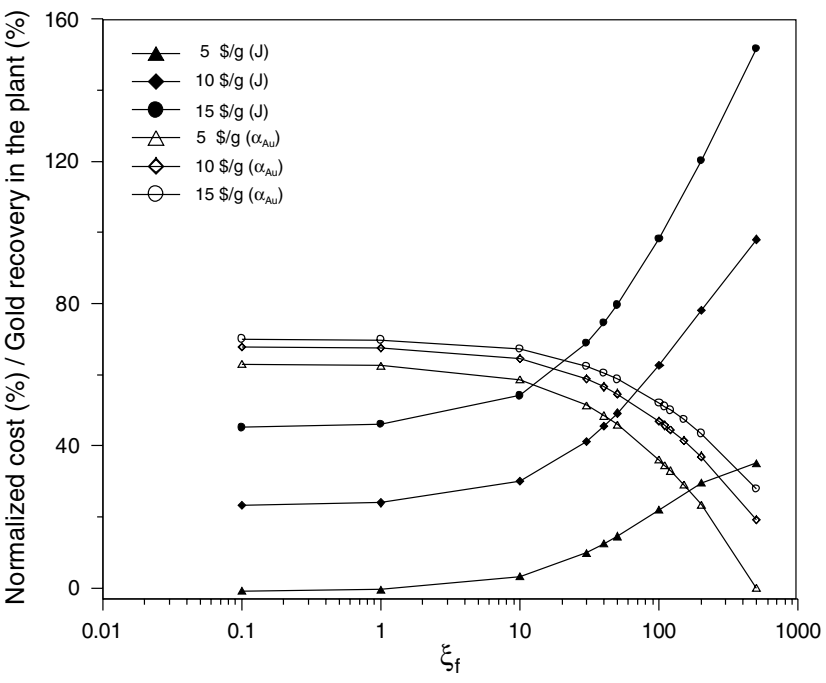

Fig. 9. Effect of cyanide consumption kinetics ( $\xi_{\mathrm{f}}$ parameter) on the normalized cost function $(J)$ and the gold recovery in the leaching plant $\left(\alpha_{\mathrm{Au}}=1-\mathrm{Cs}_{n} / \mathrm{Cs}_{0}\right)$ for three values of the gold price $\left(\operatorname{Pr}_{\mathrm{Au}}\right)$.

one adds the same quantity $(330 \mathrm{~kg} / \mathrm{h})$ only in the first tank, an increase of the cost function $\left(J^{*}\right)$ from 3401 to $3406 \$ / \mathrm{h}$ is obtained, which, in this specific case, represents an annual loss of approximately $\$ 45,000$, exclusively due to an inadequate reagent distribution.

\section{Conclusions}

A steady-state simulator of a gold leaching circuit, previously calibrated to experimental data from an Australian plant, was used to systematically demonstrate that a better cyanide distribution in a leaching reactors cascade could be achieved. This study shows that there is an optimal tuning of a gold leaching circuit, which makes a trade off between the gold recovery and the reagent cost. The optimal tuning depends upon the cyanide reagent price and the cyanide reject treatment cost, and is sensitive to the gold market value. When the gold value is high, it is economically important to improve the gold recovery by increasing cyanide concentrations in the tanks. The optimal tuning of the leaching plant depends also on the extent of dissolution performed before the leaching circuit, a parameter that may vary and must be taken into account in the search for optimal leaching plant tuning. For the specific plant analyzed in this study, the simulated results show that in the case of low cyanide consumption and fast gold dissolution kinetics, the optimal distribution of the cyanide consists in feeding all the cyanide in the first tank. However, a parametric analysis conducted with respect to the gold dissolution and cyanide consumption rates shows that, in the case of very high cyanide consumption, additions in the second and even in the third tanks are required. It is expected that the results and the methodology presented in this work will be helpful to understand the reactant distribution in other leaching plants and will be useful to improve the cyanide control. 


\section{Acknowledgements}

The authors wish to thank the Conselho Nacional de Desenvolvimento Científico e Tecnológico (CNPq, Brazil) and the Federal University of Bahia (UFBa, Brazil) for their financial support to this project. Mrs. Ann Bax (Murdoch University, Australia) is gratefully acknowledged for providing the experimental data used in this study.

\section{References}

Adams, M.D., 1990. The chemical behaviour of cyanide in the extraction of gold. 1. Kinetics of cyanide loss in the presence and absence of activated carbon. Journal of the South African Institute of Mining and Metallurgy 90 (2), 37-44.

Allibone, A.H., Windh, J., Etheridge, M.A., Burton, D., Anderson, G., Edwards, P.W., Miller, A., Graves, C., Fanning, C.M., Wysoczanski, R., 1998. Timing relationships and structural controls on the location of $\mathrm{Au}-\mathrm{Cu}$ mineralization at the Boddington gold mine, western Australia. Economic Geology and the Bulletin of the Society of Economic Geologists 93 (3), 245-270.

Bax, A., 1996. Personal communication. Murdoch University, Australia.

Bazin, C., Proulx, M., 2001. Distribution of reagents down a flotation bank to improve the recovery of coarse particles. International Journal of Mineral Processing 61 (1), 1-12.

Biegler, L.T., Westerberg, A.W., Grossmann, I.E., 1997. Systematic Methods for Chemical Process Design. Prentice-Hall, NJ.

Brandt, P.J., Dempsey, P., Van Dalen, J.H., Ashkenazi, S., 1986. Cyanide monitoring and control on Anglo-American gold plants with cycad. In: Proceedings of the SAIMM International Conference on Gold, Johannesburg, South Africa, pp. 555-563.

Caron, S., Châteauneuf, J., Tardif, L., Bourassa, M., 1999. Automatic control of free cyanide at Yvan Vézina plant. CIM Bulletin 92, 55-61.

Carrier, C., Hodouin, D., Courchesne, M., 1987. Dynamic simulation of the CIP gold recovery process. In: Salter, R.S., Wyslouzil, D.M., McDonald, G.W. (Eds.), Proceedings of the International Symposium on Gold Metallurgy. Pergamon Press, pp. 309-325.

de Andrade Lima, L.R.P., 2001. Modeling, control, and optimization applied to the gold hydrometallurgy. Ph.D. Thesis, Laval University (in French).

de Andrade Lima, L.R.P., in press. Some remarks on the reactor network synthesis for gold cyanidation. Minerals Engineering, doi:10.1016/ j.mineng.2005.08.004.

de Andrade Lima, L.R.P., Hodouin, D., 2005a. Optimization of reactor volumes in gold cyanidation. Minerals Engineering 18, 671-679.

de Andrade Lima, L.R.P., Hodouin, D., 2005b. A lumped kinetic model for gold ore cyanidation. Hydrometallurgy 79 (3-4), 121-137.

de Andrade Lima, L.R.P., Hodouin, D., Bax, A., 2002. Comparison of empirical and phenomenological approaches to the analysis of gold cyanidation plant performance. In: Laplante, A. (Ed.), Proceedings of the International Symposium on Gold Recovery. CIM Special Volume no. 51 , pp. $45-55$.

Flintoff, B., 1993, Process control in hydrometallurgy. In: Proceedings of the CIM Modeling, Simulation \& Control of Hydrometallurgical Processes, pp. 175-190.

Groves, D.I., Goldfarb, R.J., Robert, F., Hart, C.J.R., 2003. Gold deposits in metamorphic belts: overview of current understanding, outstanding problems, future research, and exploration significance. Economic Geology and the Bulletin of the Society of Economic Geologists 98 (1), 1-29.

Levenspiel, O., 1999. Chemical Reaction Engineering, third ed. John Wiley \& Sons, New York.

Lorenzen, L., van Deventer, J.S.J., 1994. The interrelationship between mineral liberation and leaching behaviour. International Journal of Mineral Processing 41 (1-2), 1-15.
Lynch, A.J., Johnson, N.W., Manlapig, E.V., Thone, C.G., 1981. Mineral and Coal Flotation Circuits: Their Simulation and Control. Elsevier, Holland.

Moreira, N.E., Malcata, F.X., 1996. On the optimum distribution of enzyme feed in a cascade of CSTR's performing an enzyme-catalyzed reaction with desativation. Bioprocess Engineering 15, 301-306.

Nicol, M.J., Fleming, C.A., Cromberge, G., 1984. The adsorption of gold cyanide onto activated carbon. II: Applications of the kinetic model to multistage absorption circuits. Journal of the South African Institute of Mining and Metallurgy 84, 50-54.

Rees, K.L., van Deventer, J.S.J., 2001. Gold process modelling. I. Batch modelling of the processes of leaching, preg-robbing and adsorption onto activated carbon. Minerals Engineering 14 (8), 753-773.

Rees, K.L., van Deventer, J.S.J., Dunne, R.C., 2001. Gold process modelling. II. The effect of ore type on leaching and adsorption dynamics at Telfer gold mine. Minerals Engineering 14 (8), 887-900.

Rogans, E.J., MacIntosh, A.J., Morrison, N., Schoeman, N., 1998. Carbon-in-pulp and carbon-in-leach adsorption circuits-optimization of design using the carousel system. In: Proceedings of the Canadian Mineral Processing Conference, Ottawa, pp. 639-663.

Rowden, C.C., 1997. On-line cyanide analysis and control. In: Proceedings of the AIMM World Gold'97 Conference, Singapore.

Schubert, J.H., Barker, I.J., Swartz, C.L.E., 1993. Performance evaluation of a carbon-in-pulp plant by dynamic simulation. Journal of the South African Institute of Mining and Metallurgy 93 (11-12), 293-299.

Stange, W., 1991. The optimization of the CIP process using mathematical and economic models. Minerals Engineering 4 (12), 1279-1295.

Stange, W., 1999. The process design of gold leaching and carbon-in-pulp circuits. Journal of the South African Institute of Mining and Metallurgy 99, 13-25.

Stange, W., King, R.P., 1987. A population balance approach to the modeling of CIP process. In: Proceedings of the 20th International Symposium on the Application of Computers and Mathematics in the Mineral Industries, pp. 209-221.

Stange, W., King, R.P., Woollacott, L., 1990a. Towards more effective simulation of CIP and CIL processes. 2. A population-balance-based simulation approach. Journal of the South African Institute of Mining and Metallurgy 90, 307-314.

Stange, W., Woollacott, L., King, R.P., 1990b. Towards more effective simulation of CIP and CIL processes. 3. Validation and use of a new simulator. Journal of the South African Institute of Mining and Metallurgy 90, 323-331.

Uys, N., Thompson, D., Pearce, I., 1987. Automatic control of cyanide in leach solutions of gold plant. The South African Mechanical Engineer 37, 159-161.

van der Walt, T.J., van Deventer, J.S.J., 1992. Non-ideal behaviour in counter-current in-pulp adsorption cascades. Minerals Engineering 5 (10-12), 1401-1420.

van Deventer, J.S.J., Ross, V.E., 1991. The dynamic simulation of carbonin-pulp systems: a review of recent developments. Minerals Engineering 4 (7-11), 667-681.

Villermaux, J., 1993. Génie de la Réaction Chimique: Conception et Fonctionnement des Réacteurs, second ed. Tec \& Doc, Lavoisier, France, pp. 126-130.

Wilde, S.A., Pidgeon, R.T., 1986. Geology and geochronology of the Saddleback Greenstone-Belt in the Archean Yilgarn Block, southwestern Australia. Australian Journal of Earth Sciences 33 (4), 491501 .

Williams, D.F., Glasser, D., 1985. The modelling and simulation of processes for the absorption of gold by activated charcoal. Journal of the South African Institute of Mining and Metallurgy 85 (8), 237-243.

Wills, B.A., 1997. Mineral Processing Technology, sixth ed. ButterworthHeinemann/Elsevier Science, MA.

Woollacott, L., Stange, W., King, R.P., 1990. Towards more effective simulation of CIP and CIL processes. 1. A modelling of adsorption and leaching. Journal of the South African Institute of Mining and Metallurgy 90, 275-282. 